\title{
A 10 year follow up of parenteral gold therapy in patients with rheumatoid arthritis
}

\author{
G Bendix, A Bjelle
}

\begin{abstract}
Objectives-To study the long term tolerance of parenteral gold and subsequent drug treatment in patients with rheumatoid arthritis, including prediction of outcome and 'survival' of sequential treatments.

Methods-A retrospective cohort study of 376 patients was made, including a detailed screening of 237 patients treated in 1989. Reasons for discontinuing treatment were analysed in life table analyses, which were used to compare patients receiving parenteral gold treatment in 1985 and 1989, and two groups of patients receiving disease modifying antirheumatic drugs after parenteral gold treatment. The causes of discontinuation were followed in sequential treatments.
\end{abstract}

Results-The estimated probability of discontinuation of parenteral gold treatment was $29 \%$ after six months and $42 \%, 55 \%$, $74 \%$, and $92 \%$ after $1,2,5$, and 10 years, respectively. Mucocutaneous side effects were the main cause of discontinuation of parenteral gold treatment during the first three years, while the probability of discontinuation because of inefficacy dominated after four years. Side effects also constituted the main cause of discontinuation of treatments given after parenteral gold treatment during the first three years of follow up. No significant differences were found when comparing the termination rates between the first and the second and subsequent treatments after parenteral gold treatment. The main reasons for discontinuing one treatment could not predict the cause of discontinuation of the next treatment.

Conclusion-Mucocutaneous side effects dominated initially, while inefficacy was the dominating cause of discontinuation of long term parenteral gold treatment. No serious side effects were registered. The cause of discontinuation of one treatment did not predict the cause of discontinuation of the following drug. Drug 'survival' was the same in both treatments after parenteral gold treatment.

(Ann Rheum Dis 1996; 55: 169-176)

The short term efficacy of parenteral gold treatment in rheumatoid arthritis (RA) has been demonstrated in controlled clinical trials, ${ }^{1-8}$ by meta-analysis, ${ }^{910}$ and in a recent study. ${ }^{11}$ Since maintenance treatment was introduced in the $1970 \mathrm{~s},{ }^{42-15}$ only a few long term studies have been reported. ${ }^{16-22}$ The effect of parenteral gold treatment has been questioned repeatedly, ${ }^{20}{ }^{23-25}$ and this uncertainty necessitates further long term evaluations to supplement the short term trials. Studies of discontinuation of treatment in long term regimens provide data on tolerance and can also be used indirectly as indicators of the effectiveness of a drug judged as a combination of efficacy and tolerance. ${ }^{21} 26$

In a previous study, ${ }^{27}$ the outcome resulting from change of practice based on the first follow up data was studied. The findings encouraged us to continue parenteral gold treatment for longer periods, disregarding minor side effects. As a result, we can now present a 10 year follow up of parenteral gold treatment in RA patients. The outcome of the treatment during two periods was compared, and the implications for patients after discontinuing parenteral gold treatment were studied, including life table analysis of the subsequent drug treatments.

\section{Patients and methods}

PATIENTS

One cohort included every patient prescribed parenteral gold treatment during all or part of 1989 at the Department of Rheumatology, Sahlgrenska University Hospital, Gothenburg, Sweden-237 patients in all (table 1). Two of these patients started parenteral gold treatment in 1980; two, five, nine, $19,34,20,20$, and 59 patients, respectively, started it in the following years until 1989, when 67 patients were included. The clinical notes for all patients were retrieved and followed until the end of 1992. A second cohort, described in detail previously ${ }^{27}$ and comprising 210 patients prescribed parenteral gold treatment in 1985 and followed up to the end of 1987 , were used for comparison; they were also included in an additional life table analysis of the total risk of discontinuation of parenteral gold treatment. In that study, the 71 patients who were treated both in 1985 and in 1989 were included only in the former group.

The main reason for discontinuing parenteral gold treatment was recorded. The outcome was studied by comparing patient data at the start of treatment with those at the end of treatment, or on the occasion of the last examination if treatment was continued past the time when this study ended in December 1992. All patients were included in the life table analysis, while only patients receiving parenteral gold treatment for a period of more than two months were included in the study of efficacy. 
Table 1 Data on rheumatoid arthritis patients prescribed parenteral gold during all or part of 1985 and 1989

\begin{tabular}{lcc}
\hline & Year of treatment & \\
\cline { 2 - 3 } & 1985 & 1989 \\
& $(n=71)$ & $(n=71)$ \\
\hline Number of patients on gold & 2225 & 2375 \\
Number of patients in the study & 210 & 237 \\
Dropout rate (\%) & 5 & 0 \\
Mean age (years) & $54(16-76)$ & $55(19-82)$ \\
Mean disease duration (years) & $7 \cdot 3(0-50)$ & $7 \cdot 6(0-46)$ \\
Male/female & $1 / 2 \cdot 4$ & $1 / 2 \cdot 5$ \\
Glucocorticoid treated (\%) & 14 & 11 \\
ARA (1958) criteria (\% of total) & 40 & 36 \\
Classical & 55 & 62 \\
Definite & 5 & 2 \\
Probable & 69 & $80^{\star}$ \\
Rheumatoid factor titre $\geqslant 80$ (\%) & 73 & 76 \\
Radiographic erosions before treatment $(\%)$ & $1343(10-5080)$ & $2295(10-7450)$ \\
Mean dose of gold (mg) $\dagger$ & $24(0-84)$ & $49(0-144)$ \\
Mean treatment duration (months) $\dagger$ & $26(3-84)$ & $51(4-144)$ \\
Mean treatment duration $>2$ months & 69 & 73 \\
Other DMARDs previous to gold (\%) & 30 & 35 \\
1 previous drug & 22 & 21 \\
2 previous drugs & 10 & 9 \\
3 previous drugs & 7 & 8 \\
>4 previous drugs & 54 & 53 \\
Antimalarials & 16 & 22 \\
Parenteral gold & 30 & 22 \\
d-Penicillamine & 2 & $17 \star \star \star$ \\
Auranofin & 5 & $11^{\star}$ \\
Sulphasalazine & 13 & 11 \\
Proresid & 6 & \\
Azathioprine, methotrexate, others & & \\
\hline & & \\
\hline
\end{tabular}

Values in parentheses are ranges.

Significance of difference between patients treated in 1985 and in 1989: ${ }^{\star} p<0.05 ;{ }^{\star \star} p<<0.001$. $\$ 71$ patients belonged to both groups.

tNot tested for significant differences between patient groups.

The patients exposed to one or several disease modifying antirheumatic drugs (DMARDs) subsequent to parenteral gold treatment were followed in the same way as those receiving parenteral gold treatment, to permit life table analyses for the first choice of DMARD, and for the second and subsequent DMARDs together. Thus, in the latter group, a patient could be included several times.

PRESCRIPTION OF PARENTERAL GOLD

Data from 1977 to 1992 were obtained from the National Corporation of Swedish Pharmacies, Stockholm, which registers sales of all drugs to pharmacies in Sweden. Drug sales are given in defined daily doses (DDD) per 1000 inhabitants per day. The DDD for sodium aurothiomalate was $2.4 \mathrm{mg}$ throughout the observation period.

PARENTERAL GOLD THERAPY

Individualised dosages of sodium aurothiomalate (Myocrisin) were given, generally $20-40 \mathrm{mg}$ in weekly intramuscular injections. When the patient was in partial or complete remission, the interval between injections was prolonged to every two to six weeks, with unchanged dosage. If a relapse occurred, the interval was decreased again.

\section{METHODS}

The following symptoms, signs, laboratory tests, and examinations were recorded from the clinical notes: American Rheumatism Association (ARA) 1958 criteria for $R A,{ }^{28}$ and the ARA remission criteria $;{ }^{29}$ morning stiffness (in minutes); presence or absence of pain on motion and at rest, joint swelling, fatigue, and nodules (no grading); rheumatoid factor (determined by the sheep cell haemagglutination test $^{30}$ ); antinuclear antibody (ANA) test; ${ }^{31}$ erythrocyte sedimentation rate (ESR) per hour; C reactive protein (CRP) $(\mu \mathrm{g} / \mathrm{ml})$; radiographic findings in joints; dermatitis, symptoms from mucous membranes, and other side effects; lack or loss of efficacy.

\section{STATISTICAL METHODS}

In the life table analysis, ${ }^{32}$ the risk of discontinuation of parenteral gold treatment and of DMARDs after parenteral gold treatment was studied using hazard functions (incidences per month) of time from the start of the treatment. The method of left censorship was applied regarding parenteral gold treatment. ${ }^{33}$ Thus patients starting parenteral gold treatment before 1985 or 1989 only contributed to the estimates of the hazard functions with the observation periods after 1 January 1985 or 1989 and up to 1987 or 1992 , respectively. The duration of treatment up to 1 January 1985 or 1989 dictated at which point these observation periods were added to the estimates of the hazard functions. The proportion of patients discontinuing treatment before a particular point of time was calculated by the use of the general relationship between distribution and hazard functions. The 95\% confidence intervals for the proportion were determined. Mantel-Haenszel's procedure ${ }^{34}$ was applied for comparisons of the risk of discontinuation of treatment between patients receiving parenteral gold treatment in 1985 and in 1989, and between the two subsequent groups of DMARDs after parenteral gold treatment.

The efficacy of the treatment was studied by Fisher's test for paired comparisons. ${ }^{35}$ The relationship between measures of disease severity plus demographic data, and the risk of discontinuation of parenteral gold treatment, was assessed by applying a special survival test. $^{36}$ To evaluate the outcome with respect to side effects and inefficacy of one treatment depending on the outcome of the previous one, Fisher's exact test was applied to a $2 \times 2$ table including only those patients discontinuing treatment as a result of side effects or inefficacy of both drugs. All tests were two tailed.

\section{Results}

PRESCRIPTION DATA 1977-92

The sale of sodium aurothiomalate in Sweden increased from negligible amounts to $0 \cdot 15$ DDD/1000 inhabitants/day during the period 1977 to 1992 (fig 1). In Gothenburg, the sale was greater from the mid 1980 s, reaching 0.40 DDD/1000 inhabitants/day. A temporary decrease was noted in 1987-88, and a tendency to decreased prescription was noted in 1992.

TOLERANCE IN PATIENTS TREATED IN 1989

At follow up at the end of 1992,82 of 237 patients $(35 \%)$ who had started parenteral gold 


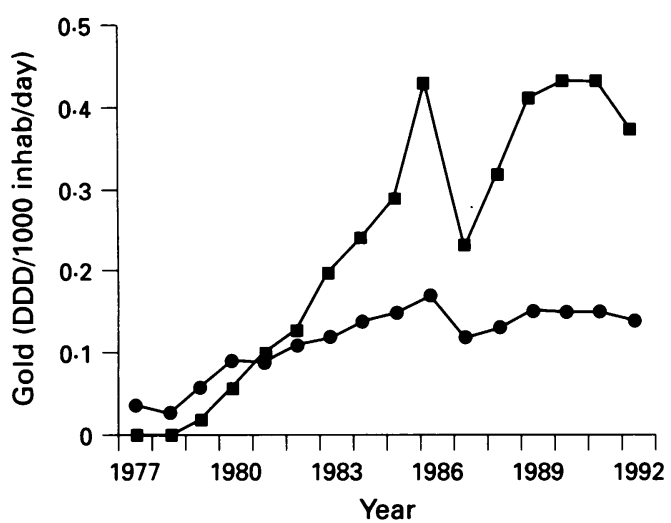

Figure 1 Prescription of parenteral gold in defined daily doses (DDD) per 1000 inhabitants (inhab) per day in all Sweden (O) and in Gothenburg ( $)$ during the years 1977-92.

treatment were still receiving this treatment, and $155(65 \%)$ had discontinued it (table 2). Inefficacy was the dominating cause of discontinuation of treatment $(46 \%)$, followed by mucocutaneous side effects $(23 \%)$, and practical problems $(18 \%)$. In five cases $(3 \%)$, the treatment was stopped because of complete remission.

The estimated probability of discontinuation (accumulated termination incidence) of parenteral gold treatment according to the life table analysis was $25 \%$ after six months, $42 \%$ after one year and $55 \%, 66 \%, 72 \%, 77 \%$, and $94 \%$ after two, three, four, five, and 10 years, respectively (fig 2). Among individual causes of discontinuation of treatment, mucocutaneous side effects dominated during the first three years, but were less common later on. After four years, inefficacy was the dominating cause of discontinuation of treatment, the probability of discontinuation being $17 \%, 37 \%, 50 \%$, $66 \%$, and $78 \%$ after two, four, six, eight, and 10 years, respectively. The hazard function

Table 2 Main reasons for discontinuing parenteral gold treatment

\begin{tabular}{lcc}
\hline & 1985 & 1989 \\
& $(\%)$ & $(\%)$ \\
\hline Mucocutaneous & $(25)$ & $(23)$ \\
Pruritus & 14 & 13 \\
Dermatitis & 4 & 7 \\
Stomatitis & 7 & 3 \\
Renal & $(6)$ & $(3)$ \\
Proteinuria & 5 & 2 \\
Haematuria & 1 & 1 \\
Haematological & $(6)$ & $(4)$ \\
Anaemia & 1 & 1 \\
Leucopenia & 2 & 1 \\
Eosinophilia & 3 & \\
Thrombocytopenia & $(3)$ & 2 \\
Gastrointestinal & 3 & \\
Aminotransferase increased & 1 & \\
Immunological (ANA positive) & & 2 \\
Nervous system & 5 & 1 \\
Postinjection reaction & 26 & 18 \\
Practical problems, etc & 25 & 46 \\
No response & 3 & 3 \\
Remission & 119 & 155 \\
Total number of patients & & \\
\hline ANA Antinum & &
\end{tabular}

ANA = Antinuclear antibody.

Figure 2 Life table analysis of total and individual risks of discontinuation of parenteral gold treatment among all 237 patients prescribed this drug during all or part of the year 1989. Censoring to the left implies that patients starting gold treatment before 1 fanuary 1989 only contributed to the observation time from that date. The duration of treatment up to that date dictated at which point from time 0 this period entered the life table analysis. The probability of discontinuation of treatment for each single reason was calculated on the assumption that patients did not withdraw treatment for any other reason-that is, the sum of individual risks is not equivalent to the total risk. 
(incidence per month) of discontinuing treatment as a result of inefficacy increased initially and was constant after three years. Proteinuria occurred only during the first year and the hazard function attributable to side effects other than mucocutaneous and proteinuria was low over time. The probability of discontinuation because of causes not related to side effects (for example practical problems), was similar to that of mucocutaneous side effects after six years of parenteral gold treatment.

Testing the relation between 21 background variables and the hazard function of discontinuation of parenteral gold treatment, only glucocorticoid treatment was found to be significantly related to all causes of termination of parenteral gold treatment $(p<0.001)$, in addition to inefficacy $(p<0.01)$ and side effects $(p<0.05)$. Pain at rest was negatively $(p<0.05)$ related to the hazard function of discontinuation because of side effects.

EFFICACY OF PARENTERAL GOLD TREATMENT IN PATIENTS TREATED IN 1989

Significant beneficial effects were observed in patients receiving parenteral gold treatment for more than two months (mean 51.3 (SD 31.8) months) for all ARA remission criteria ( $p<0.01$ for tiredness; $p<0.001$ for morning stiffness, pain on movement and at rest, joint swelling, and ESR) (table 3). No significant differences were recorded regarding nodules, rheumatoid factor, ANA, or CRP.

COMPARISONS BETWEEN PATIENTS RECEIVING PARENTERAL GOLD TREATMENT IN 1985 AND 1989

The only significantly different demographic or disease severity variable between the groups was a greater $(p<0.05)$ prevalence of positive rheumatoid factor tests in the 1989 cohort compared with the 1985 cohort (table 1). The mean duration of treatment, and hence the mean total dose of sodium aurothiomalate, was doubled. Seventy one patients belonged to both groups - that is, they were treated both in 1985 and in 1989. Comparing equivalent time periods, the hazard function of discontinuation from all causes was not different in 1985 and 1989, and among individual causes only mucocutaneous side effects were more common $(p<0.05)$ in patients treated in 1989 than in those treated in 1985 . No significant correlation was found between this risk and the

Table 3 Clinical and laboratory variables at the start of treatment and changes at follow up in 237 patients taking parenteral gold

\begin{tabular}{lcc}
\hline Variable & Start of treatment & Change at follow up \\
\hline Morning stiffness (minutes) & $115(85)$ & $-47(96)^{\star \star \star}$ \\
Tiredness (yes/no†) & $0 \cdot 90(0 \cdot 30)$ & $-0 \cdot 33(0 \cdot 48)^{\star \star}$ \\
Pain on motion (yes/not) & $1 \cdot 00(0 \cdot 07)$ & $-0 \cdot 15(0 \cdot 36)^{\star \star \star}$ \\
Pain at rest (yes/no†) & $0 \cdot 71(0 \cdot 45)$ & $-0 \cdot 48(0 \cdot 56)^{\star \star \star}$ \\
Joint swelling (yes/not) & $0 \cdot 99(0 \cdot 11)$ & $-0 \cdot 37(0 \cdot 49)^{\star \star \star}$ \\
Erythrocyte sedimentation rate (mm/1st h) & $49(28)$ & $-16(30)^{\star \star \star}$ \\
C reactive protein $(\mu \mathrm{g} / \mathrm{ml})$ & $42(33)$ & $-2(36)$ \\
\hline
\end{tabular}

Values are mean (SD).

tYes $=1 \cdot 0 ;$ no $=0.0$.

Significant changes: ${ }^{\star \star} \mathrm{p}<0.01 ;{ }^{\star \star \star} \mathrm{p}<0.001$. different prevalence of the rheumatoid factor in the two groups.

TOLERANCE IN PATIENTS TREATED IN 1985 AND 1989

The probability of discontinuation of parenteral gold treatment in all 376 patients together was also calculated (fig 3). The probability attributable to all causes was $29 \%$ after six months, $42 \%$ after one year and $55 \%$, $63 \%, 69 \%, 74 \%, 78 \%, 83 \%, 86 \%, 91 \%$, and $92 \%$ after two to 10 years, respectively. The probabilities attributable to individual causes were largely identical with those of the life table analysis of patients treated in 1989.

FIRST CHOICE OF DMARD TREATMENT AFTER PARENTERAL GOLD TREATMENT IN PATIENTS TREATED IN 1989

Among the 155 patients discontinuing parenteral gold treatment, $86(55 \%)$ were given alternative DMARDs. Twenty five patients entered a randomised controlled clinical trial of combination treatment with parenteral gold treatment and cyclosporin $\mathrm{A}$, and thus had to be excluded from this part of the present study. Forty four patients did not receive any other DMARD for the following reasons: complete or partial remission (22), removal away from the area (10), death (six), follow up discontinued (two), practical problems (two), and too short a time interval after discontinuation of parenteral gold treatment (two). As regards the choice of DMARD after parenteral gold treatment (table 4), methotrexate, sulphasalazine, and auranofin were the drugs most frequently used.

Among the 86 patients discontinuing parenteral gold treatment, 56 patients also discontinued the subsequent DMARD, 34 because of side effects, 15 because of inefficacy, and seven patients for othèr reasons.

Table 4 Number of drug treatments with different disease modifying antirheumatic drugs (DMARD) after parentera gold treatment in 86 of 155 patients discontinuing parenteral gold

\begin{tabular}{|c|c|c|}
\hline$D M A R D$ & $\begin{array}{l}\text { First } \\
\text { choice }\end{array}$ & $\begin{array}{l}\text { Second and } \\
\text { subsequent } \\
\text { choices }\end{array}$ \\
\hline Methotrexate (MTX) & 27 & 23 \\
\hline Sulphasalazine & 20 & 13 \\
\hline Auranofin $(\mathrm{Au})$ & 10 & 7 \\
\hline Proresidł & 9 & 12 \\
\hline Parenteral gold (PG) & 9 & 9 \\
\hline Azathioprine (Aza) & 6 & 5 \\
\hline d-Penicillamine & 1 & 5 \\
\hline Antimalarials (AntiM) & 1 & 4 \\
\hline Cyclosporin A (CyA) & & 1 \\
\hline Reumacon $\ddagger$ & & 2 \\
\hline Cyclophosphamide/methylprednisolone & & 4 \\
\hline MTX/AntiM/CyA & 1 & \\
\hline MTX/AntiM & 2 & \\
\hline CyA/AntiM & & 1 \\
\hline Aza/AntiM & & 1 \\
\hline МТX/СуA & & 1 \\
\hline MTX/CyA/AntiM & & 1 \\
\hline CyA/PG/AntiM & & 1 \\
\hline CyA/Aza & & 1 \\
\hline Au/AntiM & & 1 \\
\hline Total & 86 & 92 \\
\hline
\end{tabular}




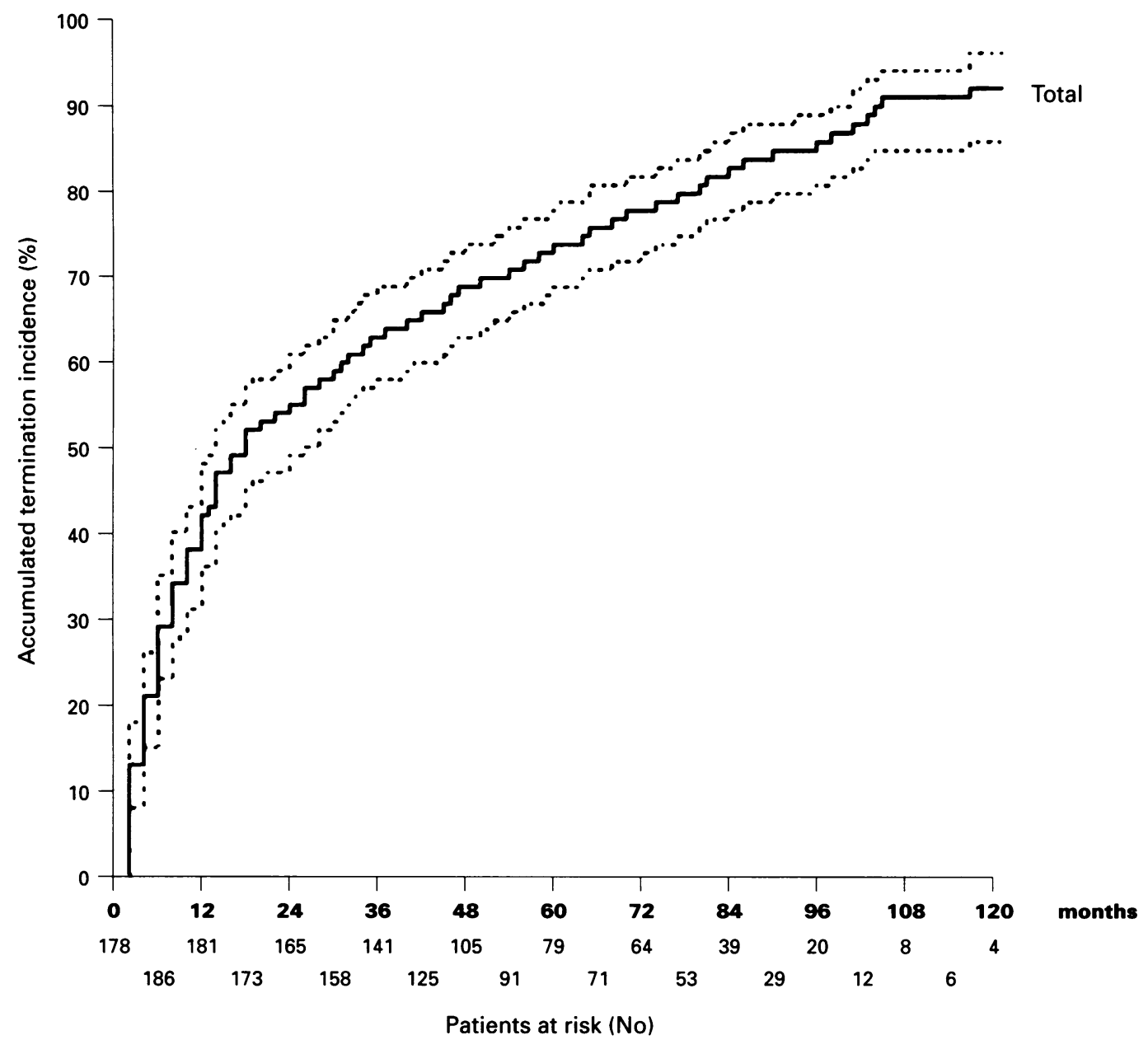

Figure 3 Life table analysis of total risk (continuous line) and 95\% confidence interval (dotted lines) of discontinuation of parenteral gold treatment among 376 patients prescribed this drug during all or part of the years 1985 and 1989. Left censoring was applied as in figure 2 .

The probability of discontinuation of the first DMARD after parenteral gold treatment as a result of all causes was $36 \%$ after six months, $53 \%$ after 12 months, $66 \%$ after 24 months, and $70 \%$ after 36 months (fig 4). Among the individual causes, side effects dominated, particularly during the first year, while inefficacy was almost as important after two years.

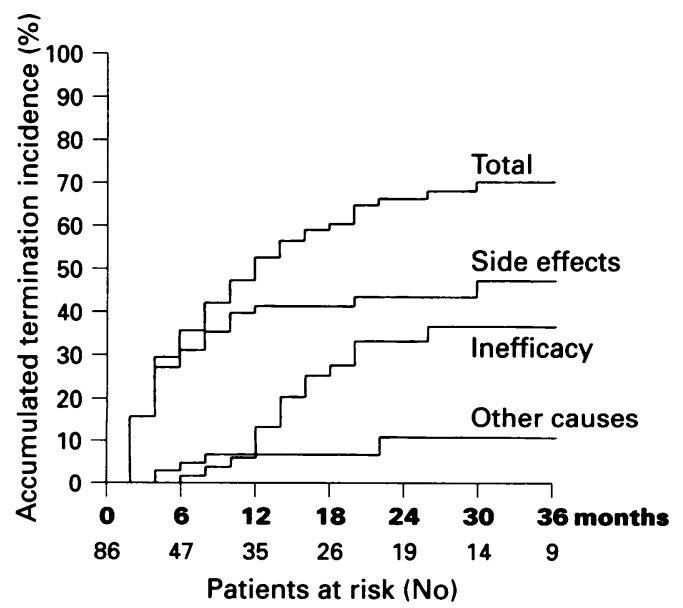

Figure 4 Life table analysis of total and individual risks of discontinuation of the first choice of disease modifying antirheumatic drug after parenteral gold treatment among 86 patients. (This treatment started after 1 fanuary 1989 and left censoring was thus not applied.)
SECOND AND SUBSEQUENT CHOICES OF DMARD TREATMENT AFTER PARENTERAL GOLD TREATMENT IN PATIENTS TREATED IN 1989 Forty four of the 56 patients who discontinued the first choice of DMARD after parenteral gold treatment were prescribed from one to six other DMARDs. The 12 remaining patients did not receive a second DMARD for the following reasons: complete or partial remission (six), renal insufficiency (one), myocardial infarction (one), death (one), practical problems (one), at the request of the patient (one), and too short a time interval after discontinuation of previous DMARD (one). A total of 92 courses of drug treatment were given to these patients (table 4). Methotrexate, sulphasalazine, and Proresid ${ }^{R}$ were the most frequently prescribed drugs. Thirty one patients $(69 \%)$ also discontinued the second DMARD, 17 because of side effects, nine because of inefficacy, and five because of other causes.

The probability of discontinuation of the second and subsequent DMARDs after parenteral gold treatment as a result of all causes was $46 \%$ after six months, $69 \%$ after 12 months, $76 \%$ after 24 months, and $83 \%$ after 36 months (fig 5). Side effects dominated among individual causes during the first year, while inefficacy was at a similar level after three years. 


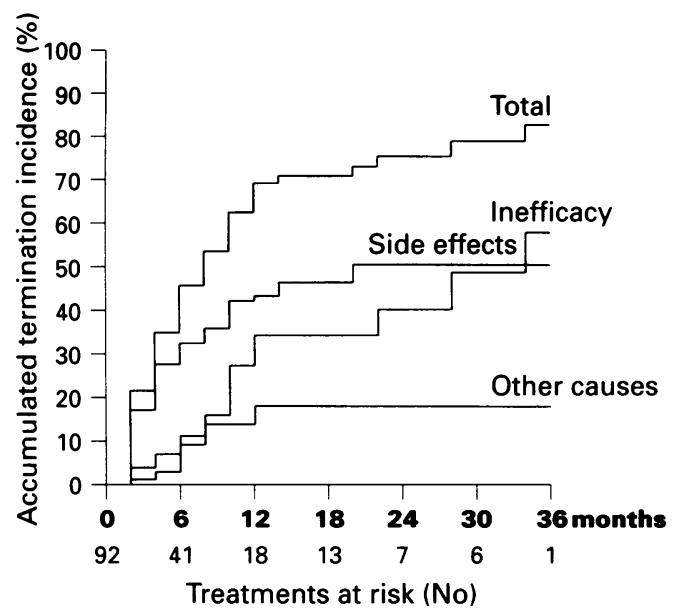

Figure 5 Life table analysis of total and individual risks of discontinuation of the second and subsequent choices of disease modifying antirheumatic drug after parenteral gold treatment (92 treatments in all). (As in figure 4, left censoring not applied.)

No significant differences were found in the life table analysis between the first and the second and subsequent DMARDs after parenteral gold treatment.

\section{EVALUATION OF TOLERANCE TO SUBSEQUENT DMARDS}

Inefficacy and side effects were studied in the 56 patients who also discontinued the first choice of subsequent DMARD after parenteral gold treatment, and in the 31 patients who subsequently discontinued the second DMARD treatment after parenteral gold treatment for these reasons. No significant differences were found between patients discontinuing the previous drug because of side effects and those discontinuing because of inefficacy, when the cause of their discontinuing the following treatment was examined. Thus the reasons for terminating parenteral gold treatment were not predictive of the reason for terminating the first or the second choice of DMARDs, nor were the reasons for terminating the first choice of DMARDs after parenteral gold treatment predictive of the reasons for terminating the second choice of DMARDs.

\section{Discussion}

In this follow up study of 376 RA patients, the total risk of discontinuation of parenteral gold treatment was $50 \%$ after 18 months and $92 \%$ after 10 years. Mucocutaneous side effects constituted the main cause of discontinuation of parenteral gold treatment during the first three years. In contrast, the hazard function of discontinuation of parenteral gold treatment because of inefficacy was constant over time after an initial increase and was the dominating cause after four years. Side effects constituted the main cause of discontinuation of subsequent DMARDs after parenteral gold treatment, while inefficacy was at a similar level after three years. Neither side effects nor inefficacy was predictive for the cause of discontinuation of the next choice of DMARD.

As a result of the findings of our previous study, ${ }^{27}$ it was decided to neglect minor mucocutaneous side effects. Despite this, the hazard function of discontinuing parenteral gold treatment for this reason was greater in the 1989 cohort than in the 1985 cohort. It was not associated with the greater prevalence of rheumatoid factor as the only difference between the patient groups. Looking for other possible explanations previously reported to be associated with skin rash, we cannot exclude an influence of IgE antibodies to gold, or smoking habits. ${ }^{37} 38$

Twelve other studies using life table analysis of parenteral gold treatment have been published. Wolfe et $a l^{21}$ reported the longest observation time of 14 years; there has been one study over a 10 year period, ${ }^{39}$ three studies with five years observation ${ }^{22} 4041$ and seven with an observation period of four years or less. ${ }^{42-48}$ Our results seem to be similar to or even slightly better than the others, with the exception of the study by Cervi et al. ${ }^{39}$ Concentrating their interest on myelotoxicity, Cervi's group also observed a lower probability of discontinuing parenteral gold treatment than we found in our study. The difference seems to depend mainly on the few patients in their study discontinuing parenteral gold treatment because of failure to respond. We used doses of parenteral gold similar to those given by Sambrook et al, ${ }^{44}$ but smaller than the more conventional doses given in the other studies specifying inefficacy. ${ }^{21} 4044-47$ However, the probability of discontinuation as a result of inefficacy was not greater in our study than in the others, with the exception of that by Situnayake et $a l,{ }^{40}$ who used retrospective data obtained during a 12 year period.

The number of patients at risk was stated in only three studies ${ }^{394344}$ and comparison between the results of our study and the previous reports is difficult, as data were collected and presented in different ways. The approach applied in the present study has the advantage that a large, well defined cohort can be used without missing subjects. This would be difficult to achieve if all subjects receiving a treatment were retrieved during a 10 year period, with underestimation of the risk of discontinuing the treatment as a consequence. Furthermore, because of the left and right censoring, the patients included in both cohorts contribute with disjointed intervals in the life table analyses. Left censoring applied to a well defined cohort can be recommended for future postmarketing surveillance studies, as it facilitates correct estimation without selection bias of the risk of discontinuing treatment because of various causes from available clinical notes.

The high probability of discontinuation because of loss of efficacy in long term parenteral gold treatment, in accordance with previous observations, ${ }^{21} 49$ has no rational explanation. Our finding of a significant association between an increased hazard function of discontinuation of parenteral gold treatment 
and concomitant glucocorticoid treatment may be attributable to chance, though it was also found in our previous study. ${ }^{50}$ We have no explanation for this finding, nor for the observation of an association between pain at rest and a decreased hazard function of discontinuation because of side effects.

No unexpected, hazardous, or longstanding side effects were observed in the patients of this study. Six patients died while receiving parenteral gold treatment: two as a result of myocardial infarction, and one each from cerebral infarction, malignant melanoma, bleeding oesophageal varices, and acute liver necrosis. Fulminant hepatic failure may result from virus infection, drugs, and miscellaneous causes. ${ }^{51}$ Watkins $e t a l^{52}$ reported two RA patients taking non-steroidal antiinflammatory drugs who developed similar symptoms after institution of parenteral gold treatment. Our patient had been taking parenteral gold treatment for nine months (total dose $650 \mathrm{mg}$ ). Paracetamol treatment was the cause most strongly suspected, though this could not be confirmed. Our overall experience of parenteral gold treatment thus confirmed it to have a relatively benign safety profile. ${ }^{53}$

There are only a few studies evaluating the sequential 'survival' of DMARD treatment. Our findings are in accordance with those reported by Pincus et $a l^{22}$ that the estimated drug continuation did not differ significantly whether the drug was the first, second, or third in line. In a study by Thompson et $a l^{54}$ comparing the probability of improvement after first, second, and third DMARD treatment, there was no significant difference between the response to the first, second, and third drug exposures, though a tendency to a reduced response was observed in the last group. Wijnands $e t a l^{47}$ found that a lower drug 'survival' was influenced by a higher rank order of DMARD prescriptions, and also reported ${ }^{55}$ that the toxicity of one DMARD did not influence the toxicity of subsequent DMARDs, which is in accordance with our findings. At the time of final assessment, continuation of DMARD treatment was not considered necessary in a total of $14 \%$ of the 1989 cohort as the patients were in remission. Three of the 11 life table studies reported on the efficacy of parenteral gold treatment. One ${ }^{44}$ mentioned the disappearance of synovitis, and the other two $^{45} 48$ reported significant improvements regarding a number of variables. The present long term study of drug tolerance was not intended to evaluate the efficacy of parenteral gold treatment, as it was confounded by placebo effects, the regression to the mean phenomenon, and the influence of frequent regular visits. ${ }^{56}$ Furthermore, efficacy may also be underrated when outcome measures are recorded at the end of treatment, excluding initial benefits. However, efficacy can be estimated indirectly from the risk of termination because of inefficacy, as the area above the inefficacy line. A drug tolerance study thus also has some value as an indicator of the effectiveness of a treatment. ${ }^{26}$
We conclude that moderate dose parenteral gold treatment carried negligible risks of serious side effects, and that the major problem in long term maintenance treatment was inefficacy. However, pending new treatment strategies, parenteral gold treatment still has a place in the active treatment of $\mathrm{RA}$, as a substantial number of patients did well during many years on this treatment.

Anders Odén, $\mathrm{PhD}$, was statistical adviser. Grants were Anders Oden, $\mathrm{PhD}$, was statistical adviser. Grants were obtained from Göteborg University, Göteborgs Läkaresällskap and from Reumatikerforeningen i Göteborg. Anders Carlsten gold.

1 Fraser T N. Gold treatment in rheumatoid arthritis. Ann Rheum Dis 1945; 4: 71-5.

2 Research Sub-Committee of the Empire Rheumatism Council. Gold therapy in rheumatoid arthritis. Final report of a multicentre controlled trial. Ann Rheum Dis 1961; 20: 315-33.

3 Cooperating Clinics Committee of the American Rheumatism Association. A controlled trial of gold salt therapy in rheumatoid arthritis. Arthritis Rheum 1973; 16: therapy

4 Sigler J W, Bluhm G B, Duncan H, Sharp J T, Ensign D C, McCrum W R. Gold salts in the treatment of rheumatoid arthritis. A double-blind study. Ann Intern Med 1974; 80: 21-6.

5 Ward J R, Williams H J, Egger M J, et al. Comparison of auranofin, gold sodium thiomalate, and placebo in the treatment of rheumatoid arthritis. A controlled clinical trial. Arthritis Rheum 1983; 26: 1303-15.

6 Pullar T, Hunter J A, Capell H A. Sulphasalazine in rheumatoid arthritis: a double blind comparison of sulphasalazine with placebo and sodium aurothiomalate. sulphasalazine with place

7 Capell H A, Lewis D, Carey J. A three year follow up of patients allocated to placebo, or oral gold or injectable gold therapy for rheumatoid arthritis. Ann Rheum Dis 1986; 45: 705-11.

8 Williams H J, Ward J R, Dahl S L, et al. A controlled trial comparing sulfasalazine, gold sodium thiomalate, and placebo in rheumatoid arthritis. Arthritis Rheum 1988; 31: 702-13.

9 Clark P, Tugwell P, Bennett K, Bombardier C. Metaanalysis of injectable gold in rheumatoid arthritis. f Rheumatol 1989; 16: 442-7.

10 Felson D T, Anderson J J, Meenan R F. Use of short-term efficacy/toxicity tradeoffs to select second-line drugs in efficacy/toxicity tradeoffs to select second-line drugs in
rheumatoid arthritis. A metaanalysis of published clinical rheumatoid arthritis. A metaanalysis of publis
trials. Arthritis Rheum 1992; 35: 1117-25.

11 Wolfe F, Hawley D J, Cathey M A. Measurement of gold treatment effect in clinical practice: Evidence for effectiveness of intramuscular gold therapy. $\mathcal{F}$ Rheumatol 1993; 20: 797-802.

12 Cats A. A multicentre controlled trial of the effects of different dosage of gold therapy, followed by a maintenance dosage. Agents Actions 1976; 6: 355-63.

13 Jessop J D. Gold in the treatment of rheumatoid arthritiswhy, when and how? f Rheumatol 1979; 6 (suppl 5): $12-7$.

14 Srinivasan R, Miller B L, Paulus H E. Long-term chrysotherapy in rheumatoid arthritis. Arthritis Rheum 1979; 22: 105-10.

15 Kean W F, Anastassiades T P. Long term chrysotherapy. Incidence of toxicity and efficacy during sequential time periods. Arthritis Rheum 1979; 22: 495-501.

16 Luukkainen R. Chrysotherapy in rheumatoid arthritis with particular emphasis on the effect of chrysotherapy on radiographical changes and on the optimal time of initiation of therapy. Scand F Rheumatol 1980; (suppl 34): $1-56$.

17 Pincus T, Callahan L F, Sale W G, Brooks A L, Payne LE, Vaughn W K. Severe functional declines, work disability, and increased mortality in seventy-five disability, and increased mortality in seventy-five rheumatoid arthritis patients studie

18 Lockie LM, Smith DM. Forty-seven years experience with gold therapy in 1,019 rheumatoid arthritis patients. Semin Arthritis Rheum 1985; 14: 238-46.

19 Mitchell D M, Spitz P W, Young D Y, Bloch D A, McShane D J, Fries J F. Survival, prognosis, and causes of death in rheumatoid arthritis. Arthritis Rheum 1986; 29: 706-14.

20 Scott D L, Symmons D P M, Coulton B L, Popert A J. Long-term outcome of treating rheumatoid arthritis: Results after 20 years. Lancet 1987 ; i: 1108-11.

21 Wolfe F, Hawley D J, Cathey M A. Termination of slow acting antirheumatic therapy in rheumatoid arthritis: A 14-year prospective evaluation of 1017 consecutive starts. 14-year prospective evaluation of 101

22 Pincus T, Marcum S B, Callahan L F. Longterm drug therapy for rheumatoid arthritis in seven rheumatology therapy for rheumatoid arthritis in seven rheumatology private practices: II. Second line
$\mathfrak{F}$ Rheumatol 1992; 19: 1885-94.

23 Epstein W V. Editorial. Parenteral gold therapy for rheumatoid arthritis: A treatment whose time has gone. f Rheumatol 1989; 16: 1291-4. 
24 Epstein W V, Henke C J, Yelin E H, Katz P P. Effect of parenterally administered gold therapy on the course of adult theumatoid arthritis. Ann Intern Med 1991; 114: 437-44.

25 Editorial. Gold therapy in rheumatoid arthritis. Lancet 1991; 338: 19-20.

26 Harth M. Gold in rheumatoid arthritis: Standard, substitute or sham? $\mathcal{F}$ Rheumatol 1993; 20: 771-3.

27 Bendix G, Bjelle A. Outcome of parenteral gold therapy in RA patients: A comparison between two periods using life-table analysis. $\mathrm{Br} \mathcal{F}$ Rheumatol 1991; 30: 407-12.

28 Ropes M W, Bennett G A, Cobb S, Jacox R, Jessar R A 1958 revision of diagnostic criteria for rheumatoid 1958 revision of diagnostic criteria
arthritis. Bull Rheum Dis $1958 ; 9: 175-6$.

29 Pinals R S, Masi A T, Larsen R A. Preliminary criteria for clinical remission in rheumatoid arthritis. Arthritis Rheum 1981; 24: 1308-15.

30 Waaler $E$. On the occurrence of a factor in human serum activating the specific agglutination of sheep blood corpuscles. Acta Pathol Microbiol Scand 1940; 7: 172-88.

31 Bergquist R. Immunofluorescence. Evaluation of techniques and reagents with special reference to methodological standardization. Thesis. Stockholm: Karolinska Institutet and the National Bacteriological Laboratory, 1974.

32 Peto R, Pike M C, Armitage $P$, et al. Design and analysis of randomized clinical trials requiring prolonged observation of each patient. II. Analysis and examples. $\mathrm{Br}$ f Cancer 1977; 35: 1-39.

33 Miller R G. Survival analysis. New York: John Wiley \& Sons, 1981;3-9.

34 Mantel N. Chi-square tests with one degree of freedom; extensions of the Mantel-Haenszel procedure. $\mathcal{F ~} \mathrm{Am}$ Stat Assoc 1963; 58: 690-700.

35 Bradley JW. Distribution-free statistical tests. London: Prentice-Hall, 1968; 68-86.

36 Merck C, Angervall L, Kindblom L-G, Odén A Myxofibrosarcoma. A malignant soft tissue tumor of fibroblastic-histiocytic origin. A clinicopathologic and fibroblastic-histiocytic origin. A clinicopathologic and prognostic study of 110 cases using multivariate analysis.
Acta Pathol Microbiol Immunol Scand $[A] 1983 ; 91$ Acta Pathol Microbio

37 Bretza J, Wells I, Novey H S. Association of IgE antibodies to sodium aurothiomalate and adverse reactions to crysotherapy for rheumatoid arthritis. $\mathrm{Am} \mathrm{f}$ Med 1983; 74: 945-50.

38 Kay E A, Jayson I V. Risk factors that may influence development of side effects of gold sodium thiomalate. Scand $₹$ Rheumatol 1987; 16: 241-5.

39 Cervi P L, Wright P, Casey E B. Audit of full blood count monitoring in patients on longterm gold therapy for

40 Situnayake R D, Grindulis K A, McConkey B. Long term treatment of rheumatoid arthritis with sulphasalazine, gold, or penicillamine: a comparison using life-table methods. Ann Rheum Dis 1987; 46: 177-83.
41 Batlle-Gualda E, Domenech-Climent V. Life table analysis of treatment terminations with gold and penicillamine in rheumatoid arthritis. Br $\mathcal{f}$ Rheumatol 1988; 27 (suppl 2): $114-5$.

42 Husain Z, Runge L A. Treatment complications of rheumatoid arthritis with gold, hydroxychloroquine, D-penicillamine, and levamisole. F Rheumatol 1980; 7: 825-30.

43 Richter J A, Runge L A, Pinals R S, Oates R P. Analysis of treatment terminations with gold and antimalarial compounds in rheumatoid arthritis. $\mathcal{F}$ Rheumatol 1980; 7: 153-9.

44 Sambrook P N, Browne C D, Champion G D, Day R O, Vallance J B, Warwick $\mathbf{N}$. Terminations of treatment with gold sodium thiomalate in rheumatoid arthritis. f Rheumatol 1982; 9: 932-4

45 Harth M, Davis P, Thompson J M, Menard H, Beaudet F Comparison between sodium aurothiomalate and auranofin in theumatoid arthritis. Scand $f$ Rheumatol 1987; 16: 177-84.

46 Morand E F, McCloud P I, Littlejohn G O. Life table analysis of 879 treatment episodes with slow acting antirheumatic drugs in community rheumatology practice. $\Im$ Rheumatol 1992; 19: 704-8.

47 Wijnands $M$ J H, van't Hof M A, van Leeuwen M A, van Rijswijk M H, van de Putte L B A, van Riel P L C M. Long-term second-line treatment: A prospective drug Long-term second-line treatment: A prospective drug survival study. Br f Rheumatol 1992; 31: 253-8.

48 Capell H A, Porter D R, Madhok R, Hunter J A. Second line (disease modifying) treatment in rheumatoid arthritis: which drug for which patient? Ann Rheum Dis 1993; 52. 423-8.

49 Rothermich N O, Philips V K, Bergen W, Thomas M H. Followup study of chrysotherapy. Arthritis Rheum 1979; 22: 423 .

50 Bendix G, Bjelle A. Proresid therapy in rheumatoid arthritis A comparison with injectable gold using life-table 51 analysis. Scand $\mathcal{F}$ Rheumatol 1993; 22: 77-82.

failure. In: Schiff L, Schiff E R, eds. Diseases of the liver, vol 2, 7th edn. Philadelphia: J B Lippincott Company, $1993 ; 1077-90$.

52 Watkins P B, Schade R, Mills A S, Carithers R L Jr, van Thiel D H. Fatal hepatic necrosis associated with parenteral gold therapy. Dig Dis Sci 1988; 33: 1025-9.

53 Fries J F, Williams C A, Ramey D, Bloch D A. The relative toxicity of disease-modifying antirheumatic drugs. Arthritis Rheum 1993; 36: 297-306.

54 Thompson P W, Kirwan J R, Barnes C G. Practical results of treatment with disease-modifying antirheumatoid of treatment with disease-modifying

55 Wijnands M J, van Riel P L, Gribnau F W, van de Putte L B. Risk factors of second-line antirheumatic drugs in theumatoid arthritis. Semin Arthritis Rheum 1990; 19: 337-52.

56 Ward M M, Leigh J P, Fries J F. Progression of functional disability in patients with rheumatoid arthritis. Arch Intern Med 1993; 153: 2229-37. 